\title{
Epileptiform syndrome in rats produced by injecting tetanus toxin into the hippocampus
}

\author{
J A N E M L L A N B Y, G R IZELDA GEORGE, AMANDA ROBINSON, \\ A N D P H IL L I P T H OMPSON
}

From the Department of Experimental Psychology, University of Oxford, Oxford

SUMMARY An epileptiform syndrome in rats produced by injecting small doses (a few (mouse) $\mathrm{LD}_{50}$ ) of tetanus toxin into the hippocampus is described. The animals had intermittent seizures, with at least a superficial resemblance to human epilepsy, for some weeks but they eventually recovered. They were hyperkinetic for several weeks after the injection of toxin, and showed intermittent aggressive behaviour. Control animals which received similar injections of tetanus toxin first neutralised with antitoxin did not have seizures, and their behaviour appeared normal. EEG recordings showed characteristic seizure activity. Histological examination of the site of injection showed very little morphological damage.

Tetanus toxin is an exceptionally potent convulsive agent-10 picogrammes are sufficient to cause convulsions and death on injection into a mouse. The convulsant action can be ascribed to the toxin's blocking transmission at inhibitory synapses in the central nervous system. Thus it has been shown to block, presynaptically, both pre- and postsynaptic inhibition in the spinal cord and cerebellum (Curtis and de Groat, 1968; Curtis et al., 1973). It also has a convulsant effect when injected into higher centres of the brain (Carrea and Lanari, 1962; Brooks and Asanuma, 1962), and this action is also likely to be due to blocking of inhibition. The toxin does not cause any obvious pathology, and sublethal doses can block synaptic transmission for weeks. Indeed, recovery of synaptic function at peripheral synapses, occurs only by resprouting of nerve terminals (Duchen, 1973; Duchen and Tonge, 1973). The toxin is a large molecule (molecular weight 145,000 ) which is rapidly bound to synaptic membranes (Mellanby and Whittaker, 1968), and it would, therefore, be unlikely to diffuse rapidly away from the site of injection if administered intracerebrally, although it might be taken up by nerve endings and translocated by retrograde axonal transport. These properties of tetanus toxin suggested that it might

\footnotetext{
Address for reprint requests: Dr Jane Mellanby, Department of Experimental Psychology, University of Oxford, South Parks Road, Oxford OX1 3UD, England.

Accepted 16 November 1976
}

prove a useful pharmacological agent for produc ing localised, long-lasting interference wit inhibitory synaptic transmission.

It has been proposed (see Meldrum, 1975) tha传 defective inhibitory transmission, particularly a $\$ \frac{7}{0}$ gamma-amino-butyric acid (GABA)-mediate synapses, is important in the genesis and spreadi $\overrightarrow{0}$ of seizures. Lesions of the hippocampus have long been considered to be associated with epilepsy, and there are many reports that epileptiform seizures can be produced in experimental animals by stimulating or making a lesion in the hippocampus (eg Green et al., 1957; and cf Green, 1964). It was, therefore, a reasonable prediction that tetanus toxin injected into the hippocampus, where it would probably block the GABA-mediated inhibition (Curtis et al., 1970), might produce epileptiform seizures. This prediction was borne out-the toxin produced a syndrome which in many ways resembled human temporal lobe epilepsy. Of particular interest was the observation that the syndrome included abnormal behaviour such as hyperkinesis and sporadic bouts of aggression. The occurrence of comparable behaviour in human patients with temporal lobe epilepsy is a matter of controversy. Where they do occur it is difficult to know whether to ascribe their causation directly to a primary epileptogenic lesion, to secondary changes in the brain brought about by seizures, or to social factors in the environment of the epileptic patient. The present findings may be relevant to this controversy. 
A preliminary report of pilot work in this investigation has been published (Mellanby and George, 1975).

\section{Materials and methods}

A tetanus toxin preparation containing $6 \times 10^{6}$ mouse $\mathrm{LD}_{50} / \mathrm{mg}$ was kindly provided by Dr R. $O$. Thomson of the Wellcome Research Laboratories. It was dissolved in gelatin-saline containing $0.2 \%$ gelatin $\mathbf{w} / \mathrm{v}$. Dilutions were made in this mixture. The toxicity of the solutions was assayed by injecting serial two-fold dilutions into the hind leg of pairs of Swiss Albino mice. One $\mathrm{LD}_{50}$ was defined as the amount of toxin which killed half the mice injected with it within seven days $(10,000$ mouse $L D_{50}$ are equivalent to 1 rat $L D_{50}$ [also injected intramuscularly]) (Mellanby and George, 1975).

Tetanus antitoxin containing 1800 units $/ \mathrm{ml}$ was also obtained from Dr R. O. Thomson. Control animals received the same amounts of the same dilutions of toxin as the experimental animals, but mixed with a just-neutralising dose of antitoxin.

Male Wistar rats weighing between 250 and $450 \mathrm{~g}$ were used. The rats were anaesthetised with a solution of chloral hydrate BP $(7 \% \mathrm{w} / \mathrm{v}$ dissolved in physiological saline), $2 \cdot 1 \mathrm{ml} / \mathrm{kg}$ body weight, and a solution of sodium pentobarbitone $(6 \% \mathrm{w} / \mathrm{v}$ Nembutal, Abbott), $0.4 \mathrm{ml} / \mathrm{kg}$ body weight. The drugs were given separately by intraperitoneal injection. The rats were then placed in a Kopf stereotaxic instrument.

\section{Injections of tetanus toxin}

Injections $(2 \times 0.5 \mu 1$ bilaterally or $1 \times 1 \mu 1$ unilaterally) were made from a $10 \mu$ l Hamilton syringe mounted in the instrument's microinjection unit.

Injections into the ventral hippocampus were made according to De Groot's Atlas of Rat Neuroanatomy, with coordinates anterior $+3.0 \mathrm{~mm}$, lateral $\pm 4.8 \mathrm{~mm}$, and vertical $-2.0 \mathrm{~mm}$.

Injections into the parafascicular nucleus of the thalamus were made according to the same Atlas, with coordinates anterior $+3.4 \mathrm{~mm}$, lateral \pm 1.1 $\mathrm{mm}$, and vertical $-0.7 \mathrm{~mm}$.

Injections into the parietal cortex were also made according to the same Atlas, with coordinates anterior $+3.4 \mathrm{~mm}$, lateral $\pm 5.2 \mathrm{~mm}$, and vertical $+3.1 \mathrm{~mm}$.

Injections into the visual cortex or the motor cortex were made using the skull sutures as guidelines.

\section{EEG records}

Screws (stainless steel $3 / 16^{\prime \prime}$ ) for recording EEG were screwed into the skull at the same operation as that at which tetanus toxin was injected. Two screws were put into the frontal and two into the occipital areas, and an earth electrode was placed in between. Leads from each screw were wired to a miniature socket, and the leads and the bottom of the socket were all embedded in dental cement on top of the head (cf Fencl et al., 1971).

EEG recordings were made from the animals for periods of several hours at a time. The socket on the head was plugged into a flexible lead (Fencl et al., 1971). The cortical potentials were led both directly via a Grass EEG amplifier to a multichannel recorder, and also through an $\mathrm{RC}$ filter giving peak output at $1.65 \mathrm{~Hz}$ (down $50 \%$ at 1 $\mathrm{Hz}$ and $4 \mathrm{~Hz}$ ) before going into a second Grass EEG amplifier. This record then gave mainly slowwave EEG activity. The filtered output was also rectified, and the mean rectified voltage was recorded on another channel, thus giving a measure of the slow wave activity.

\section{Histology}

The brains of the animals were perfused with formol saline and embedded in paraffin. They were serially sectioned at $10 \mu \mathrm{m}$, and every fifth and sixth section was stained with haematoxylin and eosin and Luxol fast blue/cresyl violet respectively. (This was kindly done by Professor L. Duchen.)

\section{OBSERVATIONS}

Each day, for four weeks after the operation, the animals were put into an open box and observed for one to three hours. Thereafter the animals were observed once a week for up to six months. During observation, a loud electric bell was rung at intervals, and the animals were also exposed for periods of several minutes to a flashing light or a clicking noise with a frequency of $6 \mathrm{~Hz}$ to $100 \mathrm{~Hz}$ (Scophony stroboscope).

Films were made of typical fits using $16 \mathrm{~mm}$ cine film at 16 frames per second. From these films information about the frequency of clonic movements was obtained by projecting the film, frame by frame, on to squared paper and recording the coordinates of the limb positions.

\section{Results}

EFFECT OF DIFFERENT DOSES OF TOXIN, ON TIMING AND DURATION OF THE EPILEPTIFORM SYNDROME The preliminary observation was made that injection of 160 mouse $\mathrm{LD}_{50}$ of tetanus toxin unilaterally into the ventral hippocampus of three 
rats led to the development of seizures on the day after the operation in all three animals. Typically, the rats would rear onto their hind feet and develop myoclonus of the upper extremities, twitching of the facial musculature, jaw movements, and chattering of the teeth. Some fits developed into running or jumping seizures during which the animals charged uncontrollably across their cage. After a fit, the animals lay passively in the cage, and seemed unaware of external stimuli. The fits occurred at frequent intervals during the day, and there were no lateralising signs referable to the unilateral site of injection. On the second day after operation, major convulsions typical of those seen in animals with generalised tetanus, developed, and the animals were not permitted to survive. Two control animals injected with 800 mouse $\mathrm{LD}_{50}$ tetanus toxin mixed with a neutralising dose of antitoxin never had fits. They ate, groomed, and explored normally, and both survived.

The dose of $160 \mathrm{LD}_{50}$ was evidently too high a dose of toxin to obtain a self-limiting epileptic syndrome, and the next step was to use much lower doses in an attempt to find the minimum dose required to produce myoclonic seizures. It was found that as little as two mouse $\mathrm{LD}_{50}$ produced such fits in three out of six rats in which it had been injected into the ventral hippocampus. With this low dose it was about two weeks before fits were seen. Somewhat higher doses (6-20 LD $\left.{ }_{50}\right)$ produced fits within the first week after the operation, and occasional fits were still seen up to two months afterwards.

The effect was then investigated more systematically. Seven rats were injected with six $\mathbf{L D}_{30}$ of tetanus toxin into the hippocampus, either divided into two doses and given bilaterally (four rats), or in one dose, given unilaterally (three rats). In five out of these seven rats fits were seen on several occasions after the operation (three bilaterally injected, two unilaterally injected) (Fig. 1). (In one of the two that did not have fits the injections had missed the hippocampus (see below) and in the other the needle tracks could not be found on histological examination.) In this experiment, the frequency of fitting in different animals varied from once in three hours to once in every half hour (as recorded during the daily observation sessions), and, in the rats which definitely received the injection into the hippocampus, the most fits were seen during the eighth to 13th days after operation. The fits then became less frequent but the animals in which the injection was near but not into the hippocampus were still having occasional fits 28 days after operation. At this stage the animals were killed and the brains perfused for histology (see below).

DESCRIPTION OF THE FITS

Typically, before a fit, the rats had a characteristic glazed expression and stood motionless with their ears held close to their heads. This phase lasted about 15 seconds. Occasionally, however, animals awoke from sleep with a seizure. The seizures usually began with clonic movements of one frong limb (like focal or Jacksonian epilepsy), but the facial muscles became bilaterally involved almos simultaneously. (In no cases of unilateral toxin ifo jection was the myoclonus more pronounced of $\vec{\theta}$ one side than the other; thus successive fits were equally likely to begin with myoclonus of either front paw.) The eyes and mouth were opened and closed, the face twitched, and the ears were held close to the head. The head was swung up and down, and often the animals reared upon their hind feet and the second front paw took up the clonic movement. Although the animals fre-

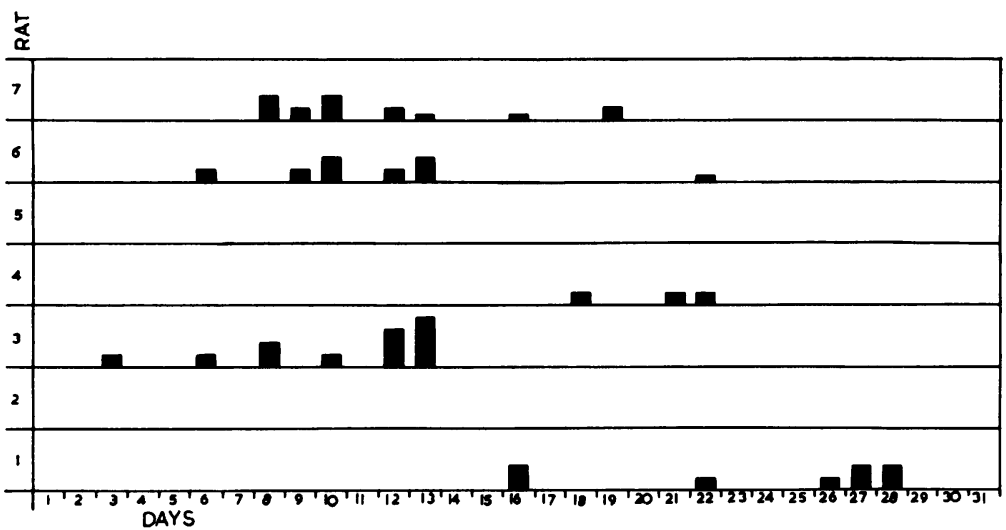

Fig. 1 Incidence of fits observed in seven rats injected with tetanus toxin (aimed stereotaxically) into the hippocampus

The sites of injection identified histologically were as follows: rat 1, bilateral, through ventral hippocampus; 의 2 , bilateral, caudate nucleus; 3 , bilateral; ventral hippocampus; 4 , bilateral, tape- $\frac{1}{0}$ tum and ? into ventricle adjacent to ventral hippocampus; 5 , unilateral, not $\mathrm{N}$ located; 6 and 7, unilateral, ventral hippocampus. The rats were observed continuously for three hours each day. Each vertical denotes one fit. 
quently fell backwards or sideways from this position, they righted themselves immediately.

Occasionally a back leg also began to jerk. Sometimes, animals had 'walking' fits during which they walked with their bodies unusually low and elongated, and exhibited the usual facial symptoms of a seizure. During such a walking fit, there was often a pause when animals had myoclonic jerks in a fore paw. The ictal stage lasted between 25 and 75 seconds after which the animals almost invariably lay quite still, and were apparently unresponsive to their surroundings. This postictal stage lasted up to four minutes. The animals would then resume normal activities, such as eating and grooming and walking round their cage, or dozing with their companions.

\section{TIMING OF MYOCLONUS}

Figure 2 shows a record, obtained by projecting single frames of a film, giving the vertical position of the front paws during a myoclonic seizure plotted against time. From this it can be seen that at first only one paw was involved, and then the other paw entered the fit as well. During some parts of the record the two paws are in phase, and in other parts they are out of phase. The behaviour, though slightly reminiscent of automated grooming, could not be described as such since the paws were not directed at the face. From this record it can be seen that the rate of myoclonic jerking was somewhat irregular at about $4 / \mathrm{s}$.
EL,ECTROENCEPHALOGRAPHIC RECORDINGS

Electroencephalograms were recorded via leads attached to the stainless steel screws inserted in the skull during the operation to inject toxin into the hippocampus. There are three traces in the records: the unfiltered EEG; the same EEG after passage through an RC filter (peaking at $1.65 \mathrm{~Hz}$ ), which shows mainly slow waves; and the filtered output also rectified, with mean rectified voltage shown on the third (relatively smooth) trace which gives a quantitative assessment of slow wave activity. The records shown in Figs. 3, 4, and 5 are all from the same rat, which had had five (mouse) $\mathrm{LD}_{50}$ of tetanus toxin injected into the left ventral hippocampus. The records are taken between electrodes screwed into the frontal and into the occipital bone on the left side (except where otherwise stated). Figure 3 shows typical waking and sleeping records taken from the rat in an interseizure period at a time after operation when it was having overt fits about once an hour. Figure 3a shows the REM sleep record (when the animal was twitching its ears and vibrissae in its sleep while its trunk muscles were relaxed). The reduction in the slow wave component in the EEG compared with slow wave sleep (Fig. 3c) is apparent. The waking EEG, taken during normal grooming and exploring behaviour, is shown (Fig. 3b) for comparison. In Fig. 4 the sleeping EEG record is compared when it is taken from the side of the head on which the toxin was originally injected (Figs. 4a and 4c), and from the

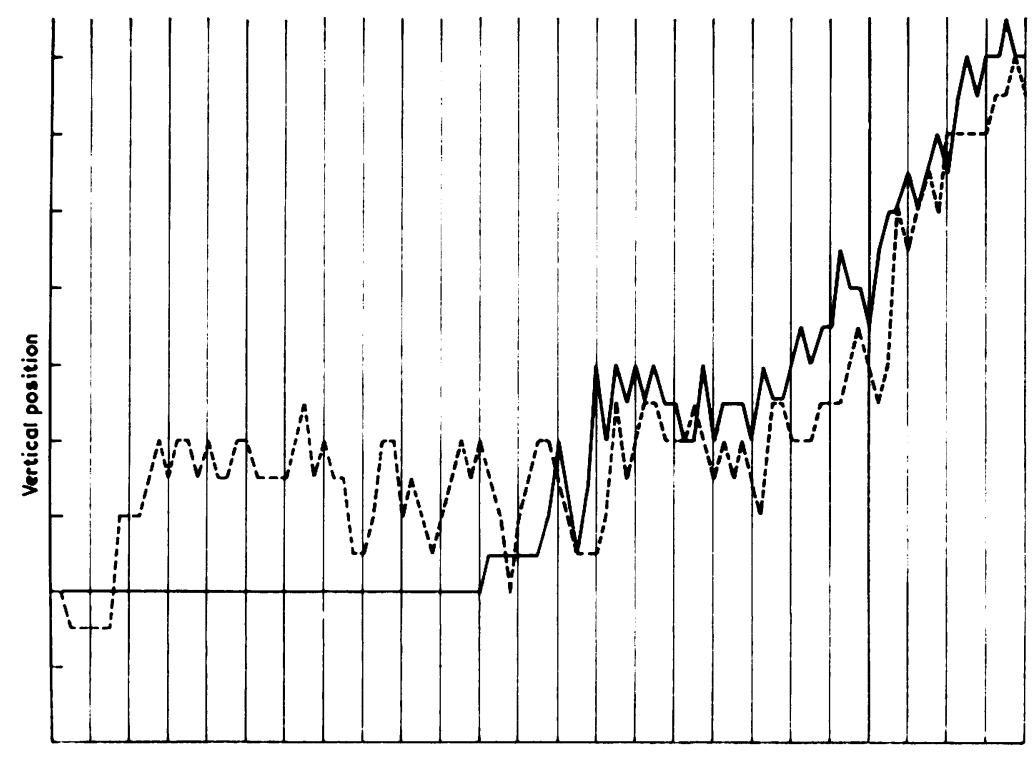

Fig. 2 Timing of myoclonus

The positions of the front paws are plotted against the frame number of the film from which they were projected and measured. The film speed was 16 frames per second. Each vertical line represents one frame on the film. The bars on the ordinate represent $1 \mathrm{~cm}$ movement of the paw. - - - right front paw; —_left front paw. 


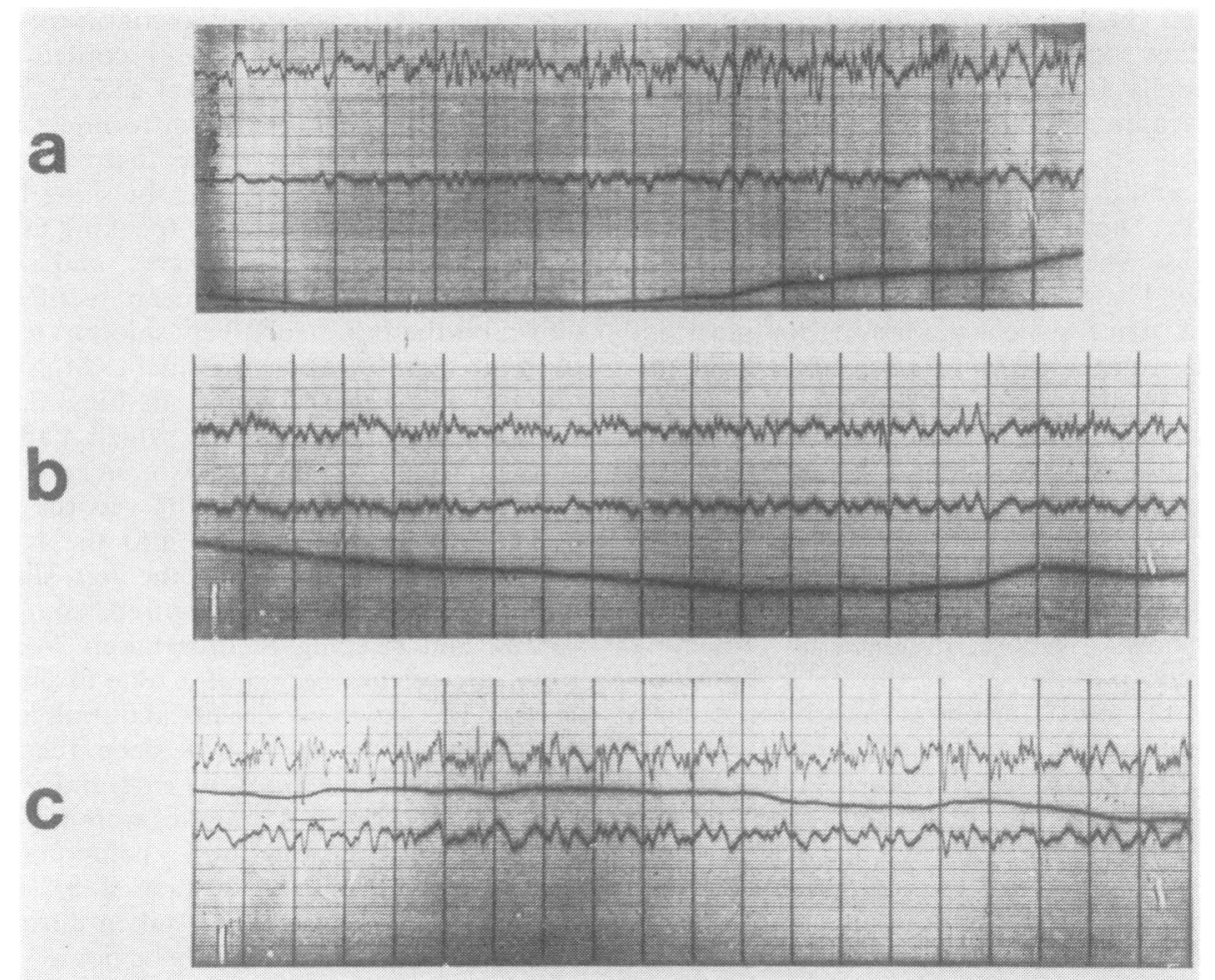

Fig 3 A comparison of the EEG in (a) REM sleep, (b) normal waking, and (c) slow wave sleep The upper trace is the unfiltered EEG record. The lower EEG record is filtered to give predominantly the slow waves
(see Methods). The third trace records the mean rectified voltage of the slow wave trace. Calibrations. Time: the trace is
divided by a vertical line at the end of each second. Voltage: distance between the more prominent horizontal lines indicates
$200 \mu \mathrm{V}$ for the upper EEG, and $260 \mu \mathrm{V}$ for the lower EEG.

opposite side (Fig. 4b). There is no striking difference between the two records.

The EEG during and after a myoclonic seizure is illustrated in Fig. 5 (a-e). Frequent fast spikes occur first (Fig. 5a) at a frequency of $8-15 \mathrm{~Hz}$. Then there are concomitant large slow waves during myoclonus (Fig. 5b) and the subsequent trancelike state (Fig. 5c) (with a frequency of about $2 \mathrm{~Hz}$ ). The slow wave activity as monitored by the trace of the mean rectified voltage is as great as ever seen in slow wave sleep in this animal (it is off the scale). The recorded slow waves have an amplitude of about $0.5 \mathrm{mV}$. The large slow waves and the frequent fast spikes then disappear as the animal returns to normal behaviour (Fig. 5c, d). There is a marked depression of the EEG for a while after recovery from the fit (Fig. 5e).
GENERAL BEHAVIOURAL OBSERVATIONS

The animals injected with tetanus toxin into the hippocampus became aggressive and hyperreactive within a few days of the operation, this change in behaviour occurring before any overt seizures were observed. The rats had to be housed individually because they attacked both each other and also normal unoperated rats. Moreover, they were extremely nervous when anyone tried to handle them, and would sometimes bite with minimal provocation. This intermittent vicious behaviour and the hyperreactivity lasted for about three weeks in the animals discussed in this paper (given $6 \mathrm{LD}_{50}$ of toxin). In another experiment (to be reported elsewhere), where 25 rats were given about twice as much toxin, the animals were still hyperractive and sporadically aggressive three months after operation but were normal by six 


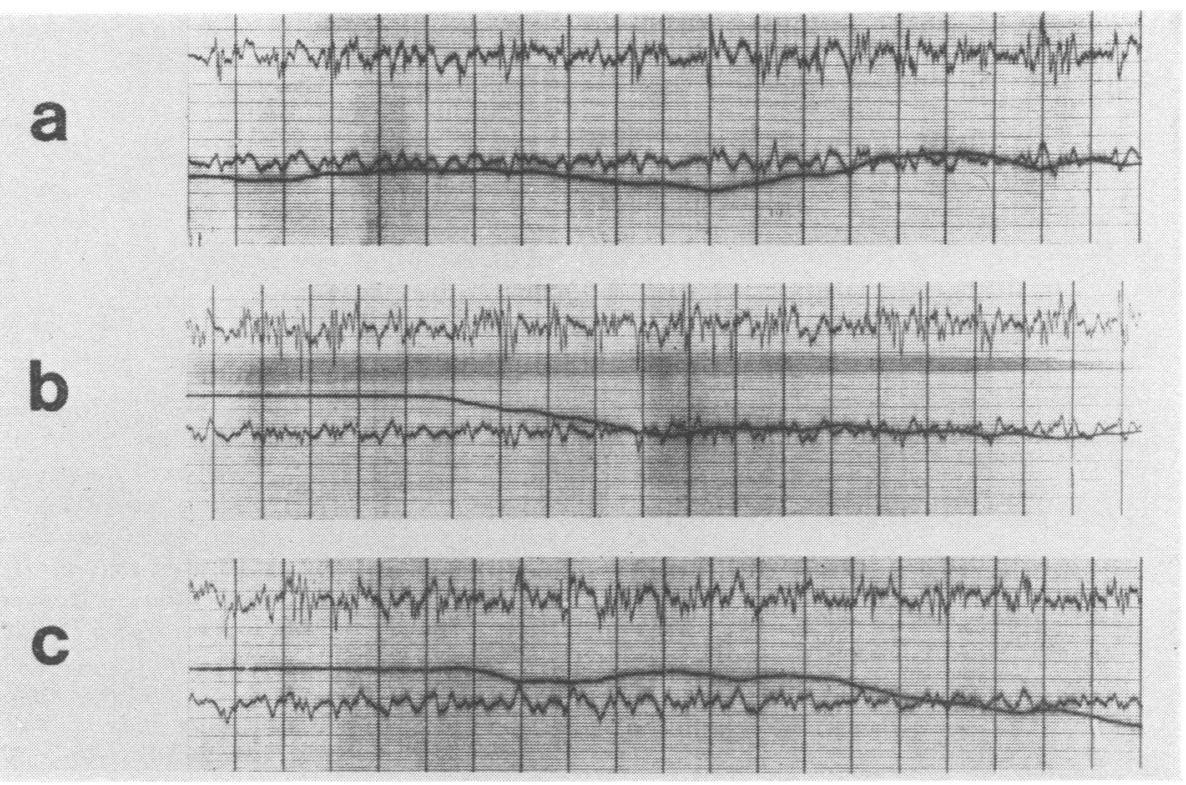

Fig. 4 The EEG, from electrodes ipsilateral ( $a$ and $c$ ), and contralateral (b) to the side on which the toxin was injected, recorded in immediate succession during sleep

For details of records see Fig. 3.

months. Control animals (injected with the toxin mixed with a neutralising dose of antitoxin) were never aggressive or difficult to handle.

In the toxin-injected animals, fits could not be provoked by clicks or by flashing lights. A sudden ring on the electric bell on only one occasion appeared to provoke a fit. However, all the animals were nervous in response to sudden noises, and many of them would react sharply to the bell by running, or jumping vertically.

\section{EFFECTS OF LOW DOSES OF TETANUS TOXIN} INJECTED INTO OTHER PARTS OF THE CEREBRAL CORTEX OR INTO THE THALAMUS

Cerebral cortex Rats were injected with low doses of tetanus toxin bilaterally into the visual cortex (two with $20 \mathrm{LD}_{50}$; two with $10 \mathrm{LD}_{50}$; three with $3 \mathrm{LD}_{50}$ ); into the motor cortex (three with $10 \mathrm{LD}_{50}$ ); or into the parietal cortex (three with $3 L_{50}$ ). None of these rats showed any abnormal behaviour at any time after operation, and they were indistinguishable from control animals injected similarly with tetanus toxin mixed with a neutralising dose of antitoxin.

Thalamus Since it is thought that in some cases of petit mal epilepsy the electroencephalographic abnormalities may originate in the thalamus (Williams, 1953, 1965), the effect of tetanus toxin injected here was investigated. Three rats were injected with three $L D_{50}$ tetanus toxin bilaterally into the thalamus (aimed at the parafascicular nucleus), and three control rats were injected into the same area with neutralised toxin. No myoclonic seizures were seen in these animals but the behaviour of those given tetanus toxin was decidedly abnormal. Between seven and 21 days after operation they were hyperactive and appeared tense, jumping vertically if disturbed. At times, however, they would sit quite still for periods of half an hour or more with their eyes open, while their apparently normal controls climbed over them. Without EEG records from these rats it is, of course, impossible to say whether this behaviour was analogous at anything more than the most superficial level to petit mal attacks. It was, however, of interest that the same dose of toxin that produced myoclonic seizures when injected into the hippocampus had such a different effect when injected into the thalamus.

HISTOL.OGICAL EXAMINATION OF THE BRAINS AFTER RECOVERY FROM FITS ENGENDERED BY INJECTION OF TETANUS TOXIN

The sites of injection were located by serially sectioning the appropriate part of the brains. In 

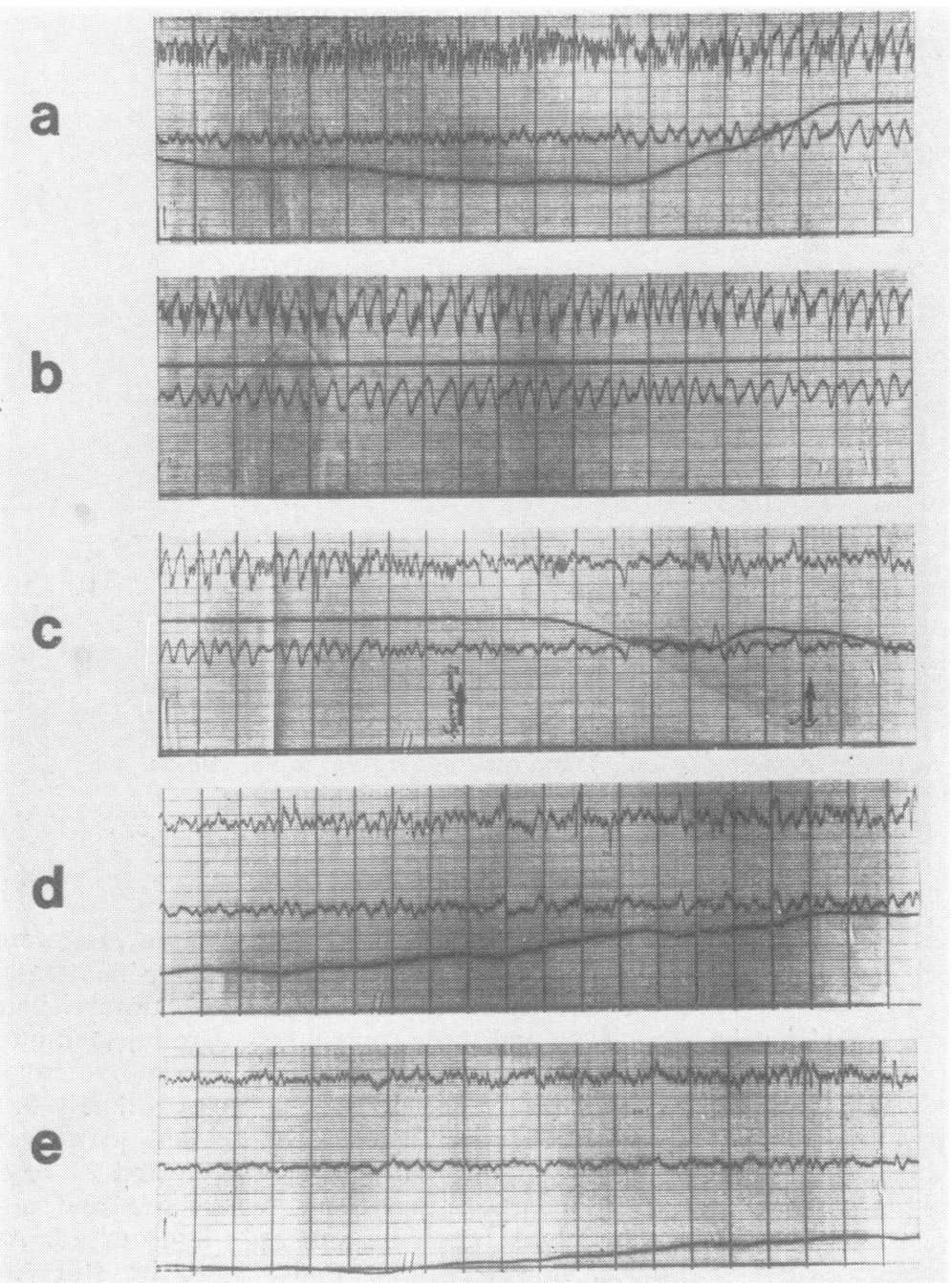

Fig. 5 The EEG during and after a fit: (a) during the first 12 seconds the rat appeared to be in a trancelike state, and then myoclonus started; (b) during myoclonus; (c) after myoclonus, a trancelike state. The rat shook its fur at the point indicated by the first arrow, and resumed normal waking activity at the second arrow; (d) follows 40 s after (c); (e) normal waking activity after the fit, showing depressed EEG activity

For details of records see Fig. 3. four out of the seven animals in which the toxin was aimed at the ventral hippocampus the needle track was identified in the hippocampus. In three of these, the track appeared to end there, but in the fourth the needle had passed right through the hippocampus. Fits were observed in all these rats but in the one in which the needle had passed through the hippocampus the fits started over a week later than in the other three. In another rat in which fits were also delayed (first seen 19 days after operation), the needle track could not be found in the hippocampus but was seen going through the tapetum and into the ventricle, adjacent to the ventral hippocampus. In the two out of the seven rats which never had fits no evidence of the needle track was found in the hippocampus. In one the injection was into the caudate nucleus, and in the other the needle tracks were never found.

In the rats in which the toxin was aimed at the parafascicular nucleus of the thalamus, although all the injection tracks were found bilaterally in the thalamus, in two cases (in different rats) the track apparently went right through the thalamus and into the medial lemniscus.

The damage done to the nervous tissue by injecting tetanus toxin (or toxin neutralised with antitoxin) into the hippocampus was minimal. Figure 6 shows the site of injection of the toxin under low and high lower. The disorganisation in 

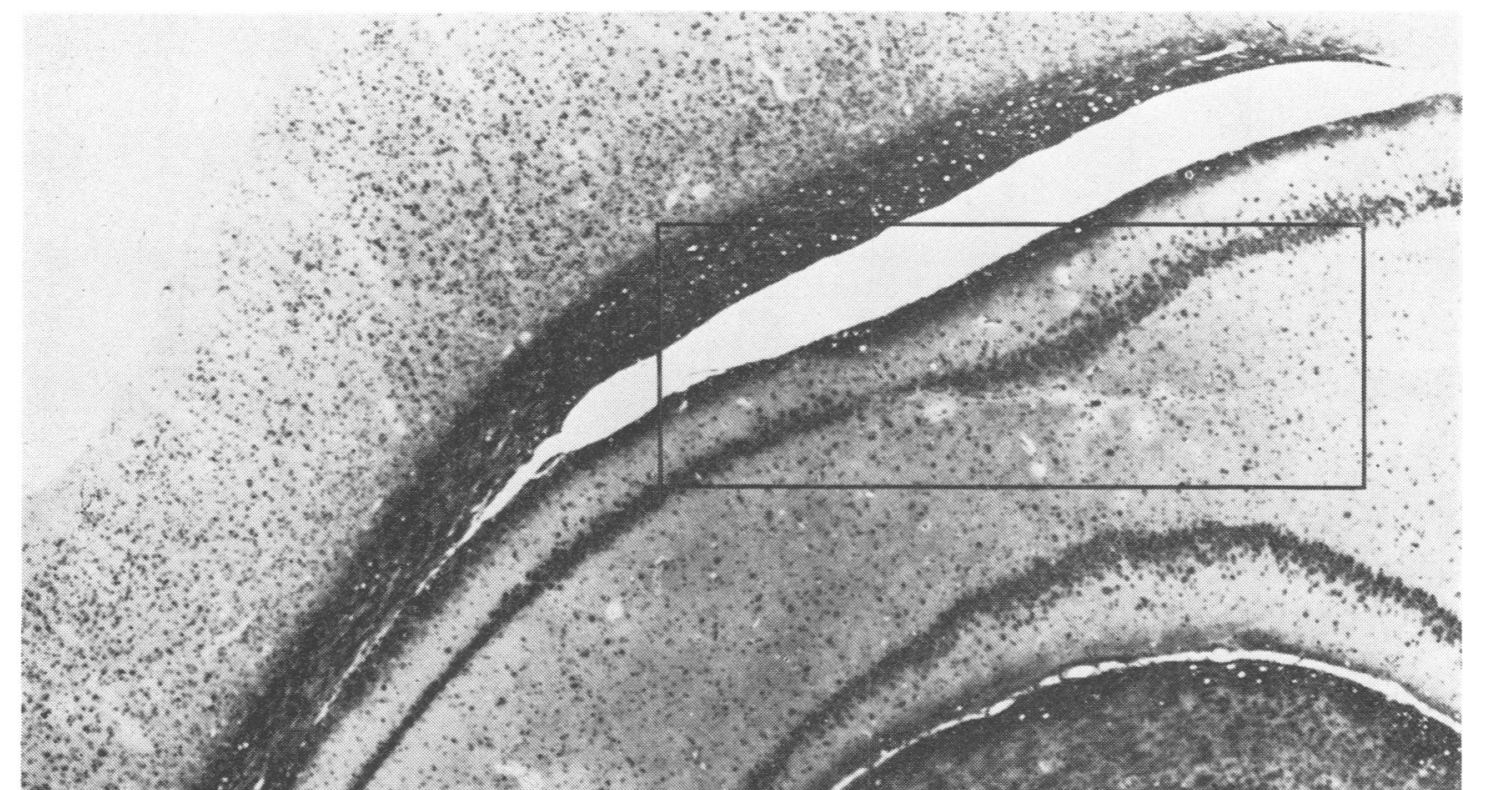

$3+2$

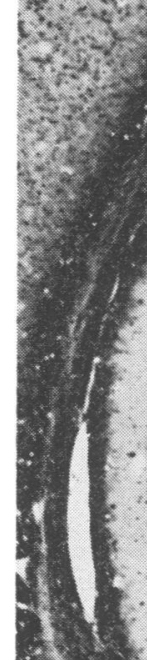
i.

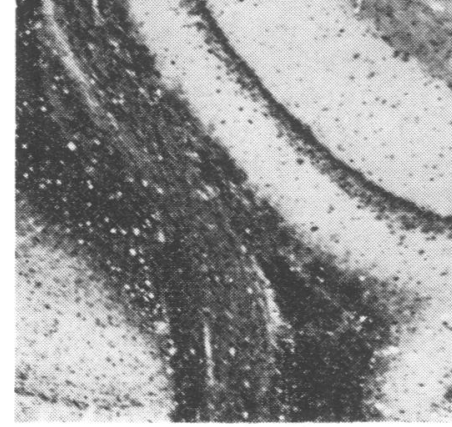

(dorsal)

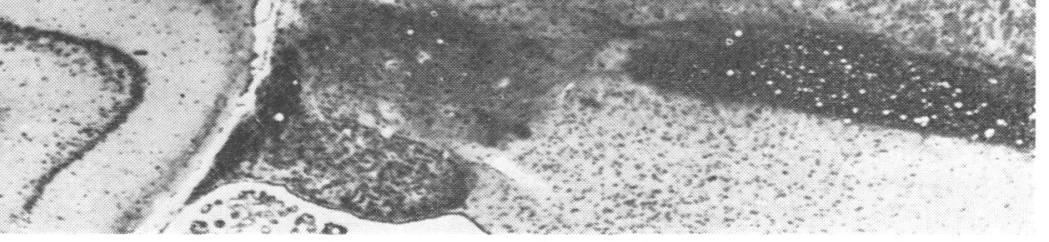

(a)

(ventral) 


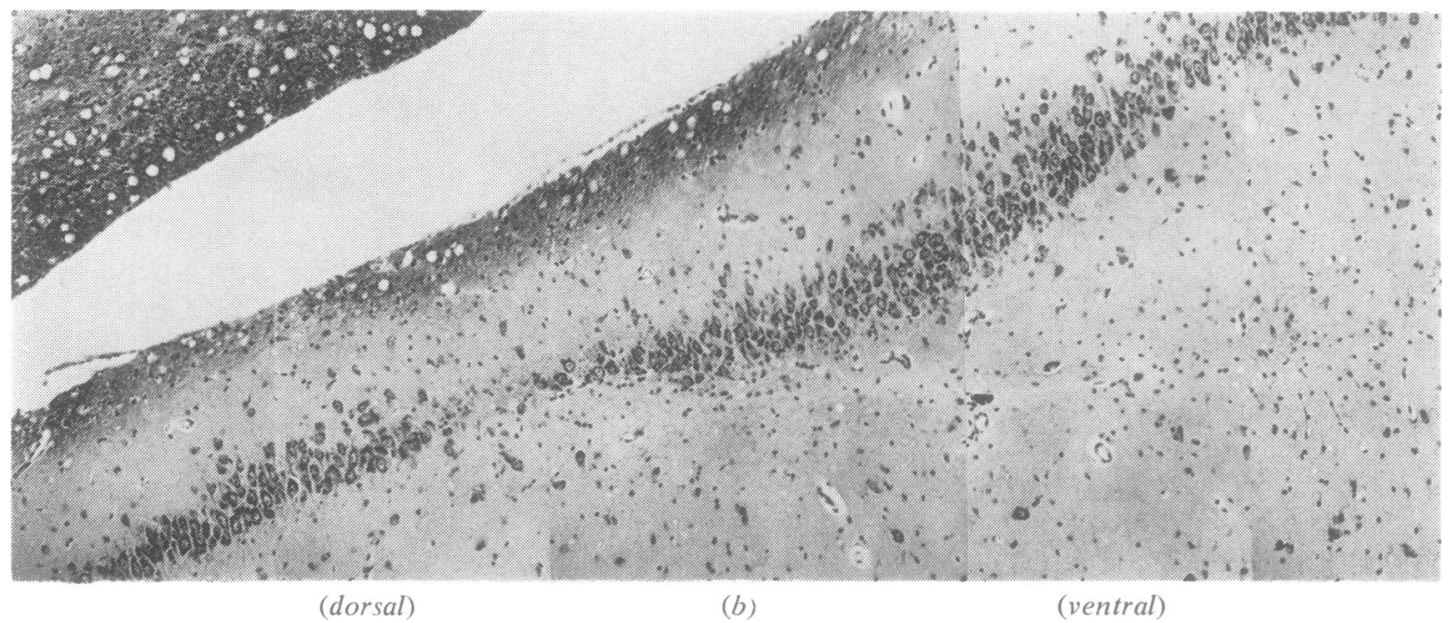

Fig. 6 Histological appearance of hippocampus 32 days after injection of $6 L D_{50}$ of tetanus toxin: (a) low power $(24 \times)$ view of transverse section of right side of brain at level of injection; $(b)$ high power (60 $\times)$ view of end of needle track in hippocampus (area indicated by square in a)

the pyramidal layer caused by the needle track is localised, and there are a few pigment granules at the site of injection. This section was taken from rat 7 in which fits had been seen between eight and 19 days after toxin injection, but in which no fits had been observed during the 12 days before the animal was killed.

\section{Discussion}

The rat is exceptionally sensitive to injection of tetanus toxin in the region of the hippocampus. Thus, at this site the injection of 5000 times less than the dose needed to kill a rat, when injected intramuscularly, leads to the development of an epileptiform syndrome (Mellanby and George, 1975).

The nature of the fits, and the electroencephalographic changes observed, bear at least a superficial resemblance to those seen in human temporal lobe epilepsy. The stage in which man experiences an aura, which is usually reported as unpleasant, and frequently involves feelings of anxiety (Currie et al., 1971), may be compared with the initial stage when the rats usually 'froze', and had their ears laid back which is considered to be an emotional response. Second, there is the stage which in man is characterised by oral automatisms and limb movements, and which was seen in the rats as facial and jaw movements, and clonic movements of the forelimbs culminating in rearing and falling. Third is the postictal stage during which, as in the corresponding stage in man, the rats were apparently unresponsive to their surroundings. The duration of each stage of the fit was within the range seen in human temporal lobe epilepsy (Blumer, 1975; Brain and Walton, 1969). Myoclonic jerks in man are variously reported to be irregular in amplitude and frequency or regular in frequency at about $3 \mathrm{~Hz}$ (Gastaut and Broughton, 1972). In the rats, the jerks were somewhat irregular at a mean frequency of about $4 \mathrm{~Hz}$. It is of interest that the rats sometimes awoke from sleep with a fit since this is a well known event in patients with temporal lobe epilepsy.

There is a division of opinion among clinicians as to whether human temporal lobe epilepsy is associated with general behavioural disturbances. Thus, for example, Currie et al. (1971), on interviewing 666 consecutive ratients with temporal lobe epilepsy, concluded that psychotic symptoms were rare, and that aggression was seen in only $7 \%$ of the ratients. In contrast, Ounsted and his colleagues (1966), after prolonged study of children with temporal lobe epilepsy, viewed psychosis as part of the disease in many patients, and described 'catastrophic rage' as a common component. This view is also supported by Glaser (Glaser et al., 1963; Glaser, 1967). It is, therefore, interesting that the rats which were injected with tetanus toxin into the hippocampus and had intermittent epileptiform seizures, showed other behavioural disturbances in the intervals between seizures. In particular, the sporadic outbursts of aggression and hyperkinesis are reminiscent of 
some clinical accounts of temporal lobe epilepsy in children. In most of the rats studied, hyperreactivity, hyperkinesis, and aggressive behaviour were observed to occur several days before overt seizures were seen. It seems likely, therefore, that the abnormal behaviour was related to the initial effects of the toxin injection, and was not a consequence of seizures.

The absence of obvious cellular damage produced by the injection of tetanus toxin, and the complete lack of abnormal behaviour observed in the control animals which were similarly injected but with neutralised toxin, makes it unlikely that the epileptogenic action of the toxin was due to scarring of the hippocampus. Just because there is so little disorganisation of the cells, it is difficult to find the precise site of toxin injection, and hence to be sure that, in order to produce the syndrome described, the tetanus toxin must be injected into the hippocampus. Although the search for other regions of the brain where injections of such small amounts of toxin might produce a similar syndrome has been far from exhaustive, the syndrome was not observed in animals in which such low doses of the toxin had been injected into the motor or parietal or visual cortex or the thalamus, or in one animal in which the toxin was accidentally injected into the caudate nucleus. Additionally, in the two rats in which the toxin was injected near but not into the ventral hippocampus, the syndrome took a week longer to develop than in animals given the same dose into the ventral hippocampus. However, the toxin may have been acting at a site distant from its site of injection. It is known that tetanus toxin injected into muscle travels from the periphery along nerves and may cross synapses to enter other nerve endings in the spinal cord (Erdmann et al., 1975; Stöckel et al., 1975). Similar transport of toxin might possibly take place when toxin is injected intracerebrally. However, the additional findings (George, Mellanby, and Rands, unpublished) that injection of toxin into the hippocampus produces effects on activity and on memory comparable with the effects of surgical lesions of the hippocampus, favours the interpretation that the tetanus toxin is interfering with hippocampal function.

The latency with which fits appeared after injection of tetanus toxin into the region of the hippocampus depended on the dose of toxin-fits were seen within 24 hours after 160 (mouse) $L D_{50}$ of toxin but not until two weeks after operation with only two $\mathrm{LD}_{50}$ of toxin. The frequency and severity of the fits, and whether they proceeded to involve generalised convulsions, were also related to the dose of toxin injected.
The mode of action of the toxin in blocking synaptic transmission presynaptically is not understood, but it apparently interferes at some point in the secretory process common to both spontaneous and evoked transmitter release (Mellanby and Thompson, 1972, 1975). It is not known why the toxin blocks transmission at some synapses and not at others. It is by no means self-evident that the effect is specific to the inhibitory synapses since tetanus toxin can block other synapses-for example, neuromuscular junctions (Ambache et al., 1948; Kryzhanovsky, 1965, 1971; Kaeser and Saner, 1970; Diamond and Mellanby, 1971; Mellanby and Thompson, 1972; Duchen and Tonge, 1973). Further experiments are needed to determine the nature of the synapses at which it blocks transmission when injected into the region of the hippocampus. However, a reasonable working hypothesis is that it is blocking the GABAmediated inhibitory synapses (Curtis et al., 1970. 1973; Storm-Mathison and Fonnum, 1971; Meldrum, 1975) in the hippocampus.

It is of general interest that the chronic epileptiform syndrome including the characteristic general behavioural changes are all reversible with time. Thus the localised 'pharmacological lesion', presumed to be produced in the hippocampus by tetanus toxin, while causing fits which may occur many times a day for as long as a fortnight, does not lead to any obvious permanent impairment in brain function. This is not unexpected in the light of the evidence (see Corsellis and Meldrum, 1976) that long periods of anoxia, such as may occur in status epilepticus, are likely to be responsible for the irrevocable neuronal damage recognised in epileptic human patients. The present work does however, suggest that abnormal inhibitory function, which may well be restricted to the hippocampus, can support a recurrent epileptiform syndrome without irreversible damage to other parts of the brain. The characteristics of the syndrome suggest that rats injected with tetanus toxin into the hippocampus may prove useful models in the study of the genesis and control of epilepsy.

We would like to thank Professor G. Glaser for his interest in the project, Professor L. Duchen for supervising the histological examination of the brains, Professor J. R. Pappenheimer for instruction and help in recording the electroencephalograms, and $\mathrm{Dr}$ G. Stores for his advice. We are grateful to Mr S. Buckingham for taking the photomicrographs, and to Mr E. G. Huckin for drawing the figures. 


\section{References}

Ambache, N., Morgan, R. S., and Wright, G. P. (1948). The action of tetanus toxin on the rabbit's iris. Journal of Physiology, 107, 45-53.

Blumer, D. (1975). In Psychiatric Aspects of Neurologic Disease. Edited by D. F. Benson and D. Blumer. Grune and Stratton: New York.

Brain, W. R., and Walton, J. N. (1969). In Brain's Diseases of the Nervous System. Oxford University Press: London.

Brooks, V. B., and Asanuma, H. (1962). Action of tetanus toxin in the cerebral cortex. Science, 137, 674-676.

Carrea, R., and Lanari, A. (1962). Chronic effect of tetanus toxin applied locally to the cerebral cortex of the dog. Science, 137, 342-343.

Corsellis, J. A. N., and Meldrum, B. S. (1976). Epilepsy. In Greenfield's Neuropathology, pp. 771796. Edited by W. Blackwood and J. A. N. Corsellis. Edward Arnold: London.

Currie, S., Heathfield, K. W. G., Henson, R. A., and Scott, D. F. (1971). Clinical course and prognosis of temporal lobe epilepsy; a survey of 666 patients. Brain, 94, 173-190.

Curtis, D. R., and de Groat, W. C. (1968). Tetanus toxin and spinal inhibition. Brain Research, 10, 208-212.

Curtis, D. R., Felix, D., Game, C. J. A., and McCullogh, R. M. (1973). Tetanus toxin and the synaptic release of GABA. Brain Research, 51, 358-362.

Curtis, D. R., Felix, D., and McLellan, H. (1970). GABA and hippocampal inhibition. British Journal of Pharmacology, 40, 881-883.

Diamond, J., and Mellanby, J. (1971). The effect of tetanus toxin in the goldfish. Journal of Physiology, 215, 727-741.

Duchen, L. W. (1973). The effects of tetanus toxin on the motor end-plates of the mouse. Journal of the Neurological Sciences, 19, 153-167.

Duchen, L. W., and Tonge, D. A. (1973). The effects of tetanus toxin on neuromuscular transmission and on the morphology of motor end plates in slow and fast skeletal muscle in the mouse. Journal of Physiology, 228, 157-172.

Erdmann, G., Wiegand, H., and Wellhoner, $H$. $H$. (1975). Intraaxonal and extraaxonal transport of $I^{125}$-tetanus toxin in early local tetanus. NaunynSchmiedeberg's Archives of Pharmacology, 290, 357-373.

Fencl, V., Koski, G., and Pappenheimer, J. R. (1971). Factors in cerebrospinal fluid from goats that affect sleep and activity in rats. Journal of Physiology, 216, 565-589.

Gastaut, H., and Broughton, R. (1972). In Epileptic Seizures: Clinical and Electrographic Features, Diagnosis and Treatment. Charles C. Thomas: Springfield, Illinois.

Glaser, G. H., Newman, R. J., and Schafer, R. (1963). Interictal psychosis in psychomotor temporal lobe epilepsy. An EEG-psychological study. In EEG and Behavior, pp. 345-365. Edited by G. H. Glaser. Basic Books: New York.

Glaser, G. H. (1967). Limbic epilepsy in childhood. Journal of Nervous and Mental Diseases, 144, 391397.

Green, J. D. (1964). The hippocampus. Physiological Reviews, 44, 561-608.

Green, J. D., Clements, C. D., and de Groot, J. (1957) Experimentally-induced epilepsy with injury to Ammon's horn. Archives of Neurology and Psychiatry (Chicago), 78, 259-263.

Kaeser, H. E., and Saner, A. (1970). Tetanus toxin, a neuromuscular blocking agent. Nature (London), 223, 842-843.

Kryzhanovsky, G. (1965). Open questions in the pathogenesis of tetanus. In Recent Advances in the Pharmacology of Toxins. Edited by H. Raudonat. Pergamon Press: Oxford.

Kryzhanovsky, G. (1971). Disturbance of the neurosecretion in neuromuscular junctions of tetanus toxin poisoned muscle. Bulletin of Experimental Biology and Medicine (Moscow), 12, 27-31.

Meldrum, B. S. (1975). Epilepsy and $\gamma$-aminobutyric acid-mediated inhibition. International Review of Neurobiology, 17, 1-36.

Mellanby, J., and George, G. (1975). Cephalic tetanus in rats. Proceedings of the IVth International Congress on Tetanus, Dakar, Senegal.

Mellanby, J., and Thompson, P. A. (1972). The effect of tetanus toxin at the neuromuscular junc tion in the goldfish. Journal of Physiology, 224, 407419.

Mellanby, J., and Thompson, P. A. (1975). The effect of lanthanum on miniature junction potentials at the goldfish neuromuscular junction after block with tetanus toxin. Journal of Physiology, 252, 8182.

Mellanby, J., and Whittaker, V. P. (1968). The fixation of tetanus toxin by synaptic membranes. Journal of Neurochemistry, 15, 205-208.

Ounsted, C., Lindsay, J., and Norman, R. (1966). Biological factors in temporal lobe epilepsy. Clinics in Developmental Medicine No. 22. The Spastics Society Medical Education and Information Unit in association with William Heinemann Medical Books Ltd.: London.

Stöckel, K., Schwab, M., and Thoenen, H. (1975) Comparison between the retrograde axonal transport of nerve growth factor and tetanus toxin in motor, sensory and adrenergic neurones. Brain $R e$ search, 99, 1-16.

Storm-Mathison, J., and Fonnum, F. (1971). Quantitative histochemistry of glutamate decarboxylase in the rat hippocampus region. Journal of Neurochemistry, 18, 1105-1111.

Williams, D. (1953). A study of thalamic and cortical rhythms in petit mal. Brain, 76, 50-69.

Williams, D. (1965). The thalamus and epilepsy. Brain, 88, 539-556. 